\title{
Prevalence and significance of Mycoplasma genitalium in women living with HIV in Denmark
}

\author{
Anne Marie Rosendahl Madsen ${ }^{1,5^{*}} \mathbb{C}$, Kristina Thorsteinsson², Anne-Mette Lebech², Merete Storgaard ${ }^{3}$, \\ Terese L. Katzenstein ${ }^{4}$, Frederikke F. Rönsholt ${ }^{4}$, Isik Somuncu Johansen ${ }^{5}$, Gitte Pedersen ${ }^{6}$, \\ Lars Noerregaard Nielsen ${ }^{7}$, Aase Bengaard Andersen ${ }^{4,5}$ and Jørgen Skov Jensen ${ }^{8}$
}

\begin{abstract}
Objective: Mycoplasma genitalium (M. genitalium) is a sexually transmitted pathogen associated with urethritis, cervicitis, and pelvic inflammatory disease. Previous studies have shown a strong association between M. genitalium and HIV infection, therefore screening and treatment for M. genitalium has been suggested as part of HIV prevention strategies. The objective of this study was to determine the prevalence of $M$. genitalium in women living with HIV (WLWH) in Denmark, and to compare the result with data on symptoms from the lower abdomen, sexual habits and immune status. 234 women, recruited from Danish HIV centres as part of a larger observational study on aspects of living with HIV as a woman (the SHADE study), were included.

Results: We tested cervical samples for M. genitalium by specific PCR. We found three samples positive (1.3\%). The women were between 30 and 50 years old, all were of Asian origin, sexually active, and on antiretroviral treatment with supressed HIV RNA and CD4 count $>350$ cells/ $\mu$ L. None reported symptoms from the lower abdomen. The prevalence of M. genitalium infection in WLWH in Denmark is low, thus systematic screening for M. genitalium in this group does not seem relevant.
\end{abstract}

Keywords: Mycoplasma genitalium, HIV, Women living with HIV, Sexually transmitted diseases

\section{Introduction}

Mycoplasma genitalium (M. genitalium) is a well-known sexually transmitted pathogen. It is an important cause of non-gonococcal urethritis in men, and in women it has been associated with cervicitis, urethritis and pelvic inflammatory disease [1]. Data from the last decade show a strong association between M. genitalium and HIV [2-4]. Women living with HIV (WLWH) infected with $M$. genitalium have been found to shed higher amounts of HIV in vaginal fluids, thereby possibly enhancing HIV transmission [5]. Infection with $M$. genitalium can lead to cervical inflammation, and it is possible that the infection

\footnotetext{
*Correspondence: Anne.Rosendahl@rsyd.dk

${ }^{1}$ Department of Clinical Microbiology, Odense University Hospital,

J.B. Winsloews Vej 21, 2, 5000 Odense C, Denmark

Full list of author information is available at the end of the article
}

also increases the risk of acquiring HIV infection, as is the case in other sexually transmitted diseases (STD) [6].

The prevalence of M. genitalium in women in the general population of high-income countries ranges from 1 to $4 \%$, but is $10 \%$ or even higher among women attending STD clinics [7-9]. In the US, a survey of WLWH showed a $9.9 \%$ prevalence of $M$. genitalium infection [10]. Studies from Africa have documented a much higher prevalence in risk groups [11]. They also documented higher prevalence of $M$. genitalium infection among HIV positive women compared with HIV negative women, and it seems the infection persists longer in the HIV positive $[12,13]$. One longitudinal study showed a twofold increased risk of being infected with HIV when M. genitalium positive [14].

Established risk factors for acquiring M. genitalium infection are young age, multiple sexual partners, 
smoking, black ethnicity, and possibly bacterial vaginosis $[9,15]$.

There are no data on M. genitalium infection in WLWH in Denmark or other parts of Scandinavia. We obtained cervical samples from WLWH participating in a larger observational study on aspects of living with HIV as a woman (the SHADE study). The aim of this study was to determine the prevalence of $M$. genitalium in WLWH in Denmark, and secondly to compare the result with data on symptoms from the lower abdomen, sexual habits and immune status.

\section{Main text \\ Registries}

The Civil Registration System (CRS) The CRS is a national registry of all Danish residents [16]. A 10-digit personal identification number (PIN) is assigned to everyone at birth or immigration. The PIN was used as a linkage to the Danish HIV Cohort Study (DHCS).

Danish HIV Cohort Study (DHCS) The DHCS is a prospective, observational, nationwide cohort study of all people living with HIV seen at the Danish HIV clinics since January 1995 [17]. From the DHCS we obtained data on baseline HIV characteristics.

\section{Methods}

\section{Study design}

We tested cervical samples collected from 234 WLWH. Women were recruited from six Danish HIV centres as part of the SHADE cohort; study on HIV, cervical abnormalities and infections in women in Denmark. The SHADE cohort is a multicenter, prospective, observational cohort study of WLWH in Denmark attending regular outpatient care for their HIV infection. The study focuses on STD, contraception, sexual activity, human papillomavirus (HPV) infection, cervical cytological abnormalities, and other aspects of living with HIV as a woman. Results from the SHADE study have been published elsewhere [18].

Women were asked to participate if they had a known HIV-1 infection and were $\geq 18$ years of age. Exclusion criteria were pregnancy and alcohol and/or drug abuse impeding adherence to the protocol. Of 1392 eligible women in the DHCS, 334 were included in the SHADE cohort. Women were enrolled between February 2011 and February 2012. The 234 WLWH included in the present study were those attending the 2 years follow-up of the SHADE study from February 2013-February 2014. At enrolment, women were tested for Chlamydia trachomatis, Neisseria gonorrhoeae, syphilis, and herpes simplex (HSV-1 and HSV-2). Gynaecological examinations were performed at entry and at 6,12 and 24 months' follow-up. An interview survey was performed to obtain background information. The questionnaire used has been described in detail elsewhere [18].

At entry, written and oral informed consent was obtained from all participants. The protocol has been approved by the Danish Data Protection Agency and by the Danish National Committee on Health Research Ethics.

\section{Study population}

The median age at inclusion in the study was 44 years (range $25-78$ years). Treatment status was generally good, with $94 \%$ of the women on antiretroviral treatment (ART), and $86 \%$ on ART with an undetectable HIV RNA. CD4 count was 350 cells/ $\mu \mathrm{L}$ or above in $80 \%$ of the cases. Symptoms from the lower abdomen were reported in $21 \%$ of the cases, most frequently vaginal discharge and abnormal menstrual bleeding. When asked about the number of lifetime sexual partners, $67 \%$ of the women reported less than 15 partners, 33\% reported more than 15 partners, and of those, $18 \%$ had more than 25 lifetime sexual partners. When asked about sexual activity in the previous 6 months up to the follow up visit, $71 \%$ were sexually active. Furthermore, $56 \%$ were married or cohabitating and $32 \%$ reported to be single. Baseline characteristics of the WLWH are listed in Table 1.

\section{Analyses}

Samples were obtained by the treating physician performing a gynecological examination. Flocked swabs were collected in UTM transport medium, and M. genitalium was detected by TaqMan ${ }^{\mathrm{TM}}$ PCR amplifying a conserved region of the $\mathrm{MgPa}$ adhesin gene [19]. Positive results were confirmed by conventional PCR amplifying the $23 \mathrm{~S}$ rRNA gene, and the resulting PCR products were subsequently sequenced to detect macrolide resistance mediating mutations [20]. The women who tested positive for M. genitalium were offered treatment with oral azithromycin for 5 days $(500 \mathrm{mg}$ day one, followed by $250 \mathrm{mg}$ daily day 2-5). Per protocol treatment in case of macrolide resistance was oral moxifloxacin $400 \mathrm{mg}$ daily for 7 days (Additional file 1).

\section{Statistical analyses}

Continuous variables were summarized as median and interquartile ranges (IQR) and compared using Wilcoxon rank sum test. Categorical variables were reported as counts and percentages and compared with Chi square test or Fisher's exact test as appropriate. Further details on the statistical analyses on the SHADE cohort have been published previously [18]. 
Table 1 Baseline characteristics of study participants ( $\mathrm{n}=\mathbf{2 3 4})$

\begin{tabular}{|c|c|}
\hline Duration of HIV infection (years), median (IQR) & $12.7(7.5-17.8)$ \\
\hline Age at inclusion (years), median (IQR) & $44.4(38.8-50.8)$ \\
\hline \multicolumn{2}{|l|}{ Race, n (\%) } \\
\hline White & $105(45.1)$ \\
\hline Asian & $32(13.7)$ \\
\hline Black & $94(40.3)$ \\
\hline Other & $2(0.9)$ \\
\hline Missing & 1 \\
\hline \multicolumn{2}{|l|}{ Place of HIV transmission, n (\%) } \\
\hline Denmark & $84(39.6)$ \\
\hline Europe + US & $16(7.6)$ \\
\hline Africa & $86(40.6)$ \\
\hline Asia & $26(12.3)$ \\
\hline Other & $0(0)$ \\
\hline Missing & 22 \\
\hline \multicolumn{2}{|l|}{ Mode of HIV transmission, n (\%) } \\
\hline Heterosexual & $210(92.5)$ \\
\hline IDU & $12(5.3)$ \\
\hline Other & $5(2.2)$ \\
\hline Missing & 7 \\
\hline \multicolumn{2}{|l|}{ CD4 count at inclusion (cells/ $\mu \mathrm{L}), \mathrm{n}(\%)$} \\
\hline$<200$ & $11(5.0)$ \\
\hline $200-350$ & $33(14.9)$ \\
\hline$>350$ & $177(80.1)$ \\
\hline Missing & 13 \\
\hline \multicolumn{2}{|l|}{ ART at inclusion, $\mathrm{n}(\%)$} \\
\hline Yes & $220(94.0)$ \\
\hline No & $14(6.0)$ \\
\hline \multicolumn{2}{|l|}{ On ART with undetectable HIV RNA ${ }^{a}, n(\%)$} \\
\hline Yes & $182(85.5)$ \\
\hline No & $31(14.6)$ \\
\hline Missing & 9 \\
\hline \multicolumn{2}{|l|}{ Lifetime sexual partners at inclusion, $n(\%)$} \\
\hline$<4$ & $58(24.8)$ \\
\hline $5-9$ & $57(24.4)$ \\
\hline $10-14$ & $40(17.1)$ \\
\hline $15-25$ & $36(15.4)$ \\
\hline $26-40$ & $13(5.5)$ \\
\hline$>40$ & $29(12.4)$ \\
\hline Does not wish to respond & $1(0.4)$ \\
\hline \multicolumn{2}{|l|}{ Sexual activity in the past 6 months, $\mathrm{n}(\%)$} \\
\hline Yes & $165(70.8)$ \\
\hline No & $68(29.2)$ \\
\hline Missing & 1 \\
\hline \multicolumn{2}{|l|}{ Symptoms from the lower abdomen, $\mathrm{n}(\%)$} \\
\hline Yes & $50(21.4)$ \\
\hline No & $184(78.6)$ \\
\hline \multicolumn{2}{|l|}{ Marital status } \\
\hline Married & $77(41.2)$ \\
\hline Cohabitating & $27(14.4)$ \\
\hline
\end{tabular}

Table 1 continued

\begin{tabular}{ll}
\hline Regular partner (not cohabitating) & $23(12.3)$ \\
Single & $60(32.1)$ \\
Missing & 47 \\
Smoking status at inclusion, $\mathrm{n}(\%)$ & \\
Current smoker/ex-smoker & $98(41.9)$ \\
Never smoker & $136(58.1)$
\end{tabular}

ART antiretroviral treatment, IDU intravenous drug use

a Undetectable $=$ HIV RNA $<40$ copies $/ \mathrm{mL}$

\section{Results}

Of the 234 women, three (1.3\%) were PCR positive for M. genitalium. All carried a macrolide susceptible strain. The prevalence was too low to perform adjusted analyses aiming at predicting associated factors.

Of the WLWH in this study, $45 \%$ were white, $40 \%$ were black and 14\% were Asian. Interestingly, all three $M$. genitalium positive women were from Asia (Thailand); thus, the prevalence among women from Asia was 10\% (95\% CI 2.0-27.0\%) which was significantly higher than the $0 \%$ prevalence found in both white and black women $(\mathrm{p}=0.01$ and $\mathrm{p}=0.02$, respectively). Characteristics of the M. genitalium positive women are shown in Table 2.

\section{Discussion}

We found a relatively low prevalence of $1.3 \%$ of M. genitalium infections in this population. The result is comparable to the prevalence of $1-4 \%$ reported in general populations in high-income countries [7-9], but much lower than in studies of African and American WLWH, where the prevalence generally has been much higher [11, 21]. Interestingly, all $M$. genitalium infected women were from Thailand. Although numbers were small, all three were infected with macrolide susceptible strains of M. genitalium, which may be surprising as the level of macrolide resistance in Thailand is expected to be high, although no precise figures exist. If the women were infected in Denmark, we would expect nearly half to carry resistance mediating mutations [20]. The low prevalence of M. genitalium could be explained by several factors. The median age is relatively high in the present study compared to other studies of both WLWH and general populations. Furthermore, the women in this population seemed to be less sexually active than WLWH in other study populations. The majority of the women were in a relationship or had a regular partner. A recent study from France showed a similar low prevalence of $M$. genitalium (3.8\%) among WLWH [22]. The study population was comparable to the present study population with respect to the median age (41.3 and 44 years respectively), race (42 and 55\% non-white respectively), and 
Table 2 Mycoplasma genitalium positive women

\begin{tabular}{|c|c|c|c|}
\hline Mycoplasma genitalium positive women & $\# 1$ & \#2 & \#3 \\
\hline Age group at inclusion (years) ${ }^{a}$ & $30-40$ & $40-50$ & $30-40$ \\
\hline Race & Asian & Asian & Asian \\
\hline Origin & Thailand & Thailand & Thailand \\
\hline Place of HIV transmission & Asia & Asia & Asia \\
\hline Mode of HIV transmission & IDU & Heterosexual & Heterosexual \\
\hline CD4 (cells/ $\mu \mathrm{L})$ & $>350$ & $>350$ & $>350$ \\
\hline HIV RNA load & Undetectable & Undetectable & Undetectable \\
\hline Smoking & Smoker & Non-smoker & Smoker \\
\hline On ART & Yes & Yes & Yes \\
\hline Sexually active & Yes & Yes & Yes \\
\hline Positive for other STD ${ }^{b}$ & No & No & No \\
\hline Lifetime sexual partners & $>40$ & $<4$ & $>40$ \\
\hline Marital status & Unknown & Married & Single \\
\hline Symptoms from the lower abdomen & None & None & None \\
\hline
\end{tabular}

IDU intravenous drug-use, ART antiretroviral treatment, STD sexually transmitted diseases

a Age is indicated as a 10-year range

b At inclusion

sexual activity. Many of the studies carried out in Africa included women in high-risk populations.

\section{Conclusions}

The prevalence of $M$. genitalium was relatively low in this study population. The result is comparable to the prevalence reported in the general populations in highincome countries. Screening for M. genitalium as part of HIV prevention strategies does not seem relevant in this setting.

\section{Limitations}

With only three positive results, there was no basis for a statistical analysis of risk factors associated with M. genitalium infection. The women who participated in this study were generally older and less sexually active than the women in most other studies of HIV and M. genitalium, and most of them were successfully treated with fully supressed HIV RNA.

\section{Additional file}

Additional file 1. Dataset with the results of $M$. genitalium PCR on the cervical samples.

\section{Abbreviations}

M. genitalium: Mycoplasma genitalium; HIV: human immunodeficiency virus; WLWH: women living with HIV; PCR: polymerase chain reaction; ART: antiretroviral treatment; STD: sexually transmitted disease; SHADE cohort: study on HIV, cervical abnormalities and infections in women in Denmark; HPV: human papillomavirus; HSV: herpes simplex virus; CRS: Civil Registration System; DHCS: Danish HIV Cohort Study; UTM: universal transport medium; Cl: confidence interval.

\section{Authors' contributions}

AMRM, KT, AML, ABA and JSJ collaborated in designing the study, data analysis, and in the writing of the manuscript. KT, AML, MS, TLK, FFR, ISJ, GP and LNN provided the samples from the different HIV centers and participated in revision of the manuscript. JSJ performed the PCR analyses in his laboratory at Statens Serum Institut. All authors read and approved the final manuscript.

\section{Author details}

${ }^{1}$ Department of Clinical Microbiology, Odense University Hospital, J.B. Winsloews Vej 21, 2, 5000 Odense C, Denmark. ${ }^{2}$ Department of Infectious Diseases, Copenhagen University Hospital, Hvidovre, Denmark. ${ }^{3}$ Department of Infectious Diseases, Aarhus University Hospital, Aarhus, Denmark. ${ }^{4}$ Department of Infectious Diseases, Copenhagen University Hospital, Rigshospitalet, Copenhagen, Denmark. ${ }^{5}$ Department of Infectious Diseases, Odense University Hospital, Odense, Denmark. ${ }^{6}$ Department of Infectious Diseases, Aalborg University Hospital, Aalborg, Denmark. ${ }^{7}$ Department of Infectious Diseases, Hillerød Hospital, Hillerød, Denmark. ${ }^{8}$ Statens Serum Institut, Copenhagen, Denmark.

\section{Acknowledgements}

We are grateful to all the WLWH for participating in the study. We further thank the staff at the clinical departments at the participating centers in the SHADE cohort: Department of Infectious Diseases, Copenhagen University Hospital, Hvidovre; Department of Infectious Diseases, Copenhagen University Hospitals, Rigshospitalet; Department of Infectious Diseases, Odense University Hospital; Department of Infectious Diseases, Aarhus University Hospital, Skejby; Department of Infectious Diseases, Aalborg University Hospital; Department of Infectious Diseases, Hillerød Hospital. Finally, we thank Niels Obel, head of the DHCS, for providing us with HIV characteristics on the WLWH from the DHCS.

Preliminary data from this study has been published in a poster at the European Conference of Clinical Microbiology and Infectious Diseases in Copenhagen in 2015.

\section{Competing interests}

AML reports non-financial support from BMS, non-financial support from Gilead and personal fees from GSK, outside the submitted work. For the remaining authors, none were declared.

Availability of data and materials

The dataset supporting the conclusions of this article is included within the article and its additional files. 


\section{Consent for publication}

Not applicable.

\section{Ethics approval and consent to participate}

The protocol has been approved by the Danish Data Protection Agency (2015-231-0126, 2012-58-0004 and 2012-41-0005) and by the Danish National Committee on Health Research Ethics (Approval Numbers: H-3-2010-119 and $\mathrm{H}-2-2014-102)$. At entry, written and oral informed consent was obtained from all participants.

\section{Funding}

This study has received funding from the Danish Female Doctors Association, The Agnethe Løvgreen Grant.

\section{Publisher's Note}

Springer Nature remains neutral with regard to jurisdictional claims in published maps and institutional affiliations.

Received: 7 March 2017 Accepted: 31 August 2017

Published online: 07 September 2017

\section{References}

1. Taylor-Robinson D, Jensen JS. Mycoplasma genitalium: from Chrysalis to multicolored butterfly. Clin Microbiol Rev. 2011;24:498-514.

2. Mavedzenge SN, Weiss HA. Association of Mycoplasma genitalium and HIV infection: a systematic review and meta-analysis. Aids. 2009;23:611-20.

3. Mavedzenge SN, Muller EE, Lewis DA, Chipato T, Morrison CS, Weiss HA. Mycoplasma genitalium is associated with increased genital HIV type 1 RNA in Zimbabwean women. J Infect Dis. 2015;211:1388-98.

4. Vandepitte J, Weiss HA, Bukenya J, Kyakuwa N, Muller E, Buve A, Van der Stuyft P, Hayes RJ, Grosskurth H. Association between Mycoplasma genitalium infection and HIV acquisition among female sex workers in Uganda: evidence from a nested case-control study. Sex Transm Infect. 2014:90:545-9.

5. Manhart LE, Mostad SB, Baeten JM, Astete SG, Mandaliya K, Totten PA. High Mycoplasma genitalium organism burden is associated with shedding of HIV-1 DNA from the cervix. J Infect Dis. 2008;197:733-6.

6. Fleming DT, Wasserheit JN. From epidemiological synergy to public health policy and practice: the contribution of other sexually transmitted diseases to sexual transmission of HIV infection. Sex Transm Infect. 1999;75:3-17.

7. Andersen B, Sokolowski I, Ostergaard L, Kjolseth Moller J, Olesen F, Jensen JS. Mycoplasma genitalium: prevalence and behavioural risk factors in the general population. Sex Transm Infect. 2007:83:237-41.

8. Weinstein SA, Stiles BG. A review of the epidemiology, diagnosis and evidence-based management of Mycoplasma genitalium. Sex Health. 2011:8:143-58.

9. Cazanave C, Manhart LE, Bebear C. Mycoplasma genitalium, an emerging sexually transmitted pathogen. Med Mal Infect. 2012;42:381-92.
10. Gatski M, Martin DH, Theall K, Amedee A, Clark RA, Dumestre J, Chhabra P, Schmidt N, Kissinger P. Mycoplasma genitalium infection among HIVpositive women: prevalence, risk factors and association with vaginal shedding. Int J STD AIDS. 2011;22:155-9.

11. Vandepitte J, Muller E, Bukenya J, Nakubulwa S, Kyakuwa N, Buve A, Weiss $H$, Hayes R, Grosskurth H. Prevalence and correlates of Mycoplasma genitalium infection among female sex workers in Kampala, Uganda. J Infect Dis. 2012;205:289-96.

12. Vandepitte J, Weiss HA, Kyakuwa N, Nakubulwa S, Muller E, Buve A, Van der Stuyft P, Hayes R, Grosskurth H. Natural history of Mycoplasma genitalium infection in a cohort of female sex workers in Kampala, Uganda. Sex Transm Dis. 2013;40:422-7.

13. Cohen CR, Nosek M, Meier A, Astete SG, Iverson-Cabral S, Mugo NR, Totten PA. Mycoplasma genitalium infection and persistence in a cohort of female sex workers in Nairobi, Kenya. Sex Transm Dis. 2007;34:274-9.

14. Mavedzenge SN, Van Der Pol B, Weiss HA, Kwok C, Mambo F, Chipato T, Van der Straten A, Salata R, Morrison C. The association between Mycoplasma genitalium and HIV-1 acquisition in African women. Aids. 2012;26:617-24.

15. Oakeshott P, Aghaizu A, Hay P, Reid F, Kerry S, Atherton H, Simms I, TaylorRobinson D, Dohn B, Jensen JS. Is Mycoplasma genitalium in women the "New Chlamydia?" A community-based prospective cohort study. Clin Infect Dis. 2010;51:1160-6.

16. Pedersen CB. The Danish Civil Registration System. Scand J Public Health. 2011;39:22-5

17. Obel N, Engsig FN, Rasmussen LD, Larsen MV, Omland LH, Sorensen HT. Cohort profile: the Danish HIV cohort study. Int J Epidemiol. 2009;38:1202-6.

18. Thorsteinsson $\mathrm{K}$, Ladelund S, Storgaard M, Ronsholt FF, Johansen IS, Pedersen G, Nielsen LN, Bonde J, Westh H, Obel N, et al. Sexually transmitted infections and use of contraceptives in women living with HIV in Denmark — the SHADE cohort. BMC Infect Dis. 2016;16:81.

19. Jensen JS, Bjornelius E, Dohn B, Lidbrink P. Use of TaqMan 5' nuclease real-time PCR for quantitative detection of Mycoplasma genitalium DNA in males with and without urethritis who were attendees at a sexually transmitted disease clinic. J Clin Microbiol. 2004;42:683-92.

20. Salado-Rasmussen K, Jensen JS. Mycoplasma genitalium testing pattern and macrolide resistance: a Danish nationwide retrospective survey. Clin Infect Dis. 2014;59:24-30.

21. Gomih-Alakija A, Ting J, Mugo N, Kwatampora J, Getman D, Chitwa M, Patel S, Gokhale M, Kimani J, Behets FS, Smith JS. Clinical characteristics associated with Mycoplasma genitalium among female sex workers in Nairobi, Kenya. J Clin Microbiol. 2014;52:3660-6.

22. Cazanave C, Lawson-Ayayi S, Hessamfar M, Neau D, Dupon M, Morlat P, Dabis F, de Barbeyrac B, Bebear C, Pereyre S. Prevalence of Mycoplasma genitalium among HIV-infected women, Agence Nationale de Recherches sur le SIDA et les hepatites virales CO3 Aquitaine Cohort, France. Sex Transm Dis. 2013:40:653-4.

\section{Submit your next manuscript to BioMed Central} and we will help you at every step:

- We accept pre-submission inquiries

- Our selector tool helps you to find the most relevant journal

- We provide round the clock customer support

- Convenient online submission

- Thorough peer review

- Inclusion in PubMed and all major indexing services

- Maximum visibility for your research

Submit your manuscript at www.biomedcentral.com/submit
Ciomed Central 